\title{
Vegetarianism and the Older Adult ${ }^{1}$
}

\author{
Kelly Johnston and Wendy J. Dahl²
}

Plant-based diets are recommended for the reduction of chronic disease risk. A vegetarian diet is a plant-based diet comprised of vegetables, fruits, whole grains, legumes, nuts and seeds, with or without dairy-based foods and eggs. If all animal-sourced foods are excluded, it is considered a vegan diet.

Vegetarian diets are becoming more popular; around 2\% of American adults over 65 years of age have taken meat, poultry, and seafood off the menu (Melina, Craig and Levin 2016). There are many reasons why vegetarian diets are gaining popularity. These include ethical concerns about animal farming and the environmental impact of our food choices, as well as the health benefits of a plant-based diet. Well-planned vegetarian and vegan diets may enhance health during all stages of life, including older adulthood. However, when following a vegetarian diet as an older adult, special attention must be paid to age-related changes to nutritional needs.

A common concern is that vegetarian diets may not provide adequate amounts of nutrients. However, most nutrient intakes of vegetarians have been found to be similar to and, for some nutrients, higher than those of non-vegetarian adults (Sobiecki et al. 2016; Melina et al. 2016). As with any diet, it is important to remember that as we age our nutritional needs change. The amount of food we need may decrease while the amount of certain nutrients we need increases. Consuming milk and other dairy products can help meet these higher nutrient needs. However, when choosing a vegan diet, it is particularly important for older adults to focus on protein, calcium, vitamin B12, and vitamin D, as well as sufficient calories (Melina et al. 2016).

\section{Getting the Energy You Need}

Keeping a healthy body weight is important for the prevention of many chronic diseases (Global Burden of Metabolic Risk Factors for Chronic Diseases Collaboration 2014). Due to decreased muscle mass, we need less calories as we age (Dhillon and Hasni 2017) and lower physical activity levels (Varma, Dey, Leroix et al. 2017); thus, it is important to choose nutrient-dense foods to help meet nutrient needs. Nutrient-dense foods are those which have more nutrients with fewer calories. A diet high in fruits, vegetables, whole grains, legumes, nuts and seeds, and foods prepared from plant-based ingredients can provide older adults with the nutrients needed without excess calories.

Some older adults may be at risk for malnutrition due to health problems. If your health care provider recommends consuming more calories to maintain or gain weight, you can focus on vegan foods that are high in healthy fats, such as nuts, seeds, and avocados.

\section{Protein Sources for a Vegan Diet}

A common concern regarding a vegan diet is whether it provides enough protein. Vegan diets provide sufficient amounts of protein if a variety of plant foods and sufficient calories are consumed. Choosing both grains and legumes helps to ensure an optimal balance of amino acids, the

1. This document is FSHN19-1, one of a series of the Food Science and Human Nutrition Department, UF/IFAS Extension. Original publication date January 2018. Visit the EDIS website at https://edis.ifas.ufl.edu for the currently supported version of this publication.

2. Kelly Johnston, graduate student; and Wendy J. Dahl, associate professor; Department of Food Science and Human Nutrition; UF/IFAS Extension, Gainesville, FL 32611.

The Institute of Food and Agricultural Sciences (IFAS) is an Equal Opportunity Institution authorized to provide research, educational information and other services only to individuals and institutions that function with non-discrimination with respect to race, creed, color, religion, age, disability, sex, sexual orientation, marital status, national origin, political opinions or affiliations. For more information on obtaining other UF/IFAS Extension publications, contact your county's UF/IFAS Extension office. 
building blocks of protein. Eating enough protein becomes more challenging as we age. For people 65 years and older, it is recommended that they consume 1.0 to 1.2 grams of protein per kilogram (2.2 pounds) of body weight per day (Bauer et al. 2013), significantly more than younger adults. For example, someone who weighs $150 \mathrm{lbs}$ should consume at least $68-82 \mathrm{~g}$ of protein each day. Older adults who engage in regular physical activity may need more as do those with chronic disease (Bauer et al. 2013). Older adults who have experienced unintended weight loss due to illness or injury may also need to consume higher amounts of protein. Choosing beans or soy-based foods (e.g. soy patties, soymilk, and edamame) available at most grocery stores may help to increase protein intake. Table 1 provides the protein content of some plant-sourced foods.

Table 1. Protein content of plant-sourced foods (USDA 2018).

\begin{tabular}{|l|c|c|}
\hline \multicolumn{1}{|c|}{ Food } & Serving size & Protein (g) \\
\hline Black beans, canned & $1 / 2$ cup & 22 \\
\hline Chickpeas, canned & $1 / 2$ cup & 20 \\
\hline Soybeans, boiled & $1 / 2$ cup & 16 \\
\hline Vegetarian patty & 2 oz & 12 \\
\hline Tofu & 3 oz slice & 8 \\
\hline Macaroni, dry & $1 / 2$ cup & 7 \\
\hline Peanut butter & 2 Tbsp & 7 \\
\hline Soymilk & 1 cup & 7 \\
\hline Sunflower seeds & $1 / 4$ cup & 6 \\
\hline Mixed nuts & $1 / 4$ cup & 5 \\
\hline Potato, baked & 1 large & 4 \\
\hline
\end{tabular}

\section{Healthy Bones}

To prevent bone loss, older adults have higher calcium recommendations than younger adults (IOM 2011). For vegans who rely on plant foods for their calcium, it is important to note that calcium is not well absorbed from some plant foods due to the content of certain substances (e.g., phytates). However, there are plant foods containing calcium that is better absorbed, such as kale, turnip greens, bok choy, white beans, almonds, figs, and oranges (Melina et al 2016). The calcium content of tofu is a good source of this mineral. To meet requirements, older adults who are vegans should include foods with added calcium in their diet, such as fortified soy milk or fortified orange juice (Melina et al. 2016).

Vitamin D is also important for bone health. As we age, our ability to make our own vitamin $\mathrm{D}$ through sun exposure decreases (Hill and Aspray 2017). To get enough vitamin $\mathrm{D}$ from a vegan diet, it is important to include foods with added vitamin D, such as non-dairy milks, fruit juices, and breakfast cereals. You can also choose mushrooms treated with UV light, as they contain vitamin D. For older adults who choose a vegetarian or vegan diet, supplemental vitamin D may be necessary (Melina et al. 2016). Supplementary vitamin D2 is always vegetarian, whereas vitamin D3 may be made from plant or animal sources. Ask your health care provider if a vitamin $\mathrm{D}$ supplement is right for you.

\section{Vitamin B12}

Vitamin B12 is not present in plant foods. In addition, older adults are at higher risk of vitamin B12 deficiency, as our ability to absorb it decreases with age (IOM 1998). Vitamin B12 may be present in tempeh, spirulina, and nutritional yeast, but these foods are not reliable sources (Melina et al. 2016). Older adults who are vegans must instead consume vitamin B12-fortified foods or supplements to prevent deficiency.

\section{Benefits of a Vegetarian Diets}

The many health benefits of plant-based diets can be experienced by those who pay attention to their changing nutritional needs as they age. Well-balanced vegetarian or vegan diets have been found to be protective and therapeutic for health problems such as obesity, heart disease, high blood pressure, diabetes, cancer, and osteoporosis (Melina et al 2016). The potential health benefits of leaving meat, poultry, and seafood off your plate has made the vegetarian diet one of three healthy eating patterns described in the 2015-2020 Dietary Guidelines for Americans (USDHHS and USDA 2015). Following a vegetarian diet as you age not only meets your nutritional needs, but may also help you to achieve optimal health.

For more resources on vegetarian diets and older adults see:

The Academy of Nutrition and Dietetics: http:// www.eatright.org/resources/food/nutrition/ vegetarian-and-special-diets

United States Department of Agriculture: www.choosemyplate.gov

Meals on Wheels: https://www.mealsonwheelsamerica.org/ 


\section{References}

Bauer, J., G. Biolo, T. Cederholm, M. Cesari, A. J. Cruz-Jentoft, J. E. Morley, S. Phillips, C. Sieber, P. Stehle, D. Teta, R. Visvanathan, E. Volpi, and Y. Boirie. 2013. "Evidence-based recommendations for optimal dietary protein intake in older people: a position paper from the PROT-AGE Study Group." J Am Med Dir Assoc 14 (8): 542-59. doi: 10.1016/j. jamda.2013.05.021.

Global Burden of Metabolic Risk Factors for Chronic Diseases Collaboration. 2014. "Cardiovascular disease, chronic kidney disease, and diabetes mortality burden of cardiometabolic risk factors from 1980 to 2010: a comparative risk assessment." Lancet Diabetes Endocrinol 2 (8): 634-47. doi: 10.1016/s22138587(14)70102-0.

Dhillon, R. J., and S. Hasni. 2017. "Pathogenesis and Management of Sarcopenia." Clin Geriatr Med 33 (1): 17-26. doi: 10.1016/j.cger.2016.08.002.

Hill, T. R., and T. J. Aspray. 2017. "The role of vitamin D in maintaining bone health in older people." Ther Adv Musculoskelet Dis 9 (4): 89-95. doi: 10.1177/1759720x17692502.

Institute of Medicine. 1998. Dietary Reference Intakes for Thiamin, Riboflavin, Niacin, Vitamin B6, Folate, Vitamin B12, Pantothenic Acid, Biotin, and Choline. Washington (DC): National Academies Press.

Institute of Medicine. 2011. Dietary Reference Intakes for Calcium and Vitamin D. Washington (DC) National Academies Press.

Melina, V., W. Craig, and S. Levin. 2016. "Position of the Academy of Nutrition and Dietetics: Vegetarian Diets." J Acad Nutr Diet 116 (12): 1970-1980. doi: 10.1016/j. jand.2016.09.025.

Sobiecki, J. G., P. N. Appleby, K. E. Bradbury, and T. J. Key. 2016. "High compliance with dietary recommendations in a cohort of meat eaters, fish eaters, vegetarians, and vegans: results from the European Prospective Investigation into Cancer and Nutrition-Oxford study." Nutr Res 36 (5): 464-77. doi: 10.1016/j.nutres.2015.12.016.

U.S. Department of Health and Human Services and U.S. Department of Agriculture. 2015 - 2020 Dietary Guidelines for Americans. 8th Edition. December 2015. Available at http://health.gov/dietaryguidelines/2015/guidelines/.
U.S. Department of Agriculture Food Products Database. "United States Department of Agriculture Website." https:// ndb.nal.usda.gov/ndb/search/list.

Varma, V. R., D. Dey, A. Leroux, J. Di, J. Urbanek, L. Xiao, and V. Zipunnikov. 2017. "Re-evaluating the effect of age on physical activity over the lifespan." Prev Med 101: 102-108. doi: 10.1016/j.ypmed.2017.05.030. 